\title{
How to keep patients un-HAPI: Cardiac surgery and sacral pressure injuries: Invited expert opinion: Hospital-acquired pressure injuries
}

Charles M. Geller, MD, and Sirivan S. Seng, MD

"A superior doctor prevents sickness; A mediocre doctor attends to impending sickness; An inferior doctor treats sickness."

—Chinese proverb

Hospital-acquired pressure injuries (HAPIs) are debilitating complications with profound consequences. Wounds resulting from the effects of prolonged mechanical tissue loading were described early on by Hippocrates ${ }^{1}$ and in the Ayurvedic system of healing. ${ }^{2}$

Cardiac surgery patients are at particular risk for the development of sacral HAPIs both during and after surgery, with a reported incidence as high as $16.7 \%$ to $29.5 \%$. $^{3-5}$ Patients who develop HAPIs suffer from associated consequences such as pain, infection, disability, and emotional distress. Direct costs related to HAPI treatment are substantial. ${ }^{6}$ It was estimated in 2007 that each HAPI adds $\$ 43,180$ in costs to a single hospital stay. ${ }^{7}$ Of US patients who develop HAPIs, $23 \%$ are acquired intraoperatively during surgeries that last longer than 3 hours, and the average estimated cost of treatment is $\$ 750$ million to $\$ 1.5$ billion per year. ${ }^{8}$ The Centers for Medicare and Medicaid Services have listed stage III and IV HAPI as "never events," adversely impacting reimbursements for the treating facility. ${ }^{9}$ Due to the significant burden HAPI places on both patients and health care organizations, prevention is critical.

\section{HAPI DEFINITION AND STAGING}

Created in 2007, the National Pressure Ulcer Advisory Panel (NPUAP) established a system for categorizing pressure injuries. It defines a pressure injury as "localized damage to the skin and underlying soft tissue usually over a bony prominence or related to a medical or other device."

From the Division of Cardiothoracic Surgery, Department of Surgery, Crozer Chester Medical Center, Upland, Pa.

Received for publication Nov 1, 2019; revisions received Nov 24, 2019; accepted for publication Dec 4, 2019; available ahead of print Feb 19, 2020.

Address for reprints: Charles M. Geller, MD, Department of Surgery, Vivacqua Pavilion, Suite 440, One Medical Center Blvd, Upland, PA 19013 (E-mail:

charles.geller@crozer.org).

J Thorac Cardiovasc Surg 2020;160:158-63

$0022-5223 / \$ 36.00$

Copyright (c) 2020 by The American Association for Thoracic Surgery

https://doi.org/10.1016/j.jtcvs.2019.12.108

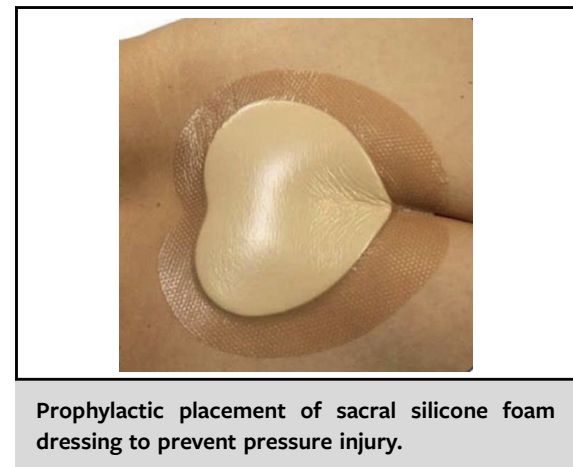

CENTRAL MESSAGE

Placement of a sacral silicone foam dressing before cardiac surgery is a cost-effective tool that prevents HAPI, thereby maximizing patient outcomes.

See Commentary on page 164

In 2016, the NPUAP and European Pressure Ulcer Advisory Panel expanded the definition of pressure ulcers to 6 different stages ${ }^{10,11}$ (Figure 1):

- Category/stage 1 pressure ulcer: non-blanchable erythema

Intact skin with non-blanchable erythema in an area usually over a bony prominence. Individuals with darkly pigmented skin may not have visible blanching.

- Category/stage 2 pressure ulcer: partial-thickness skin loss

Partial-thickness skin loss with exposed dermis that may present as a shallow open ulcer with a red or pink wound bed or as a blister.

- Category/stage 3 pressure ulcer: full-thickness skin loss

Full-thickness skin loss with exposed subcutaneous tissue. No evidence of bone, tendon, or muscle visualization.

- Category/stage 4 pressure ulcer: full-thickness tissue loss

Full-thickness tissue loss with exposed bone, tendon, or muscle directly visualized or palpable. These can extend into muscle or supporting structures, making osteomyelitis possible. 


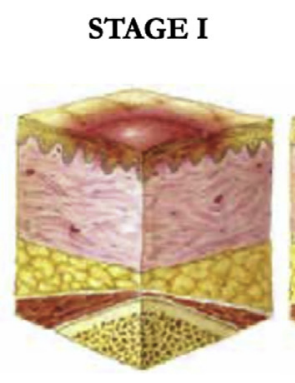

Intact skin with non-blanchable erythema
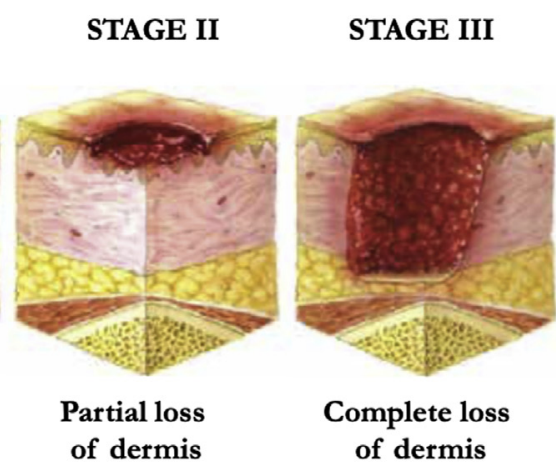

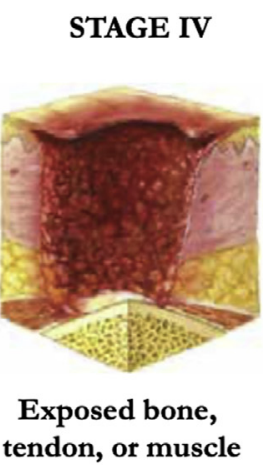

tendon, or muscle

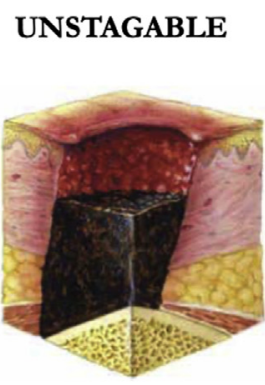

Slough or eschar obscuring depth

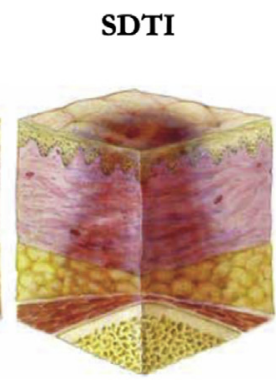

Purple or maroon discoloration of intact skin

FIGURE 1. National Pressure Ulcer Advisory Panel/European Pressure Ulcer Advisory Panel staging of pressure ulcers. SDTI, Suspected deep tissue pressure injury.

- Unstageable pressure ulcer: depth unknown

Obscured, full-thickness tissue loss in which the base of the wound is covered by slough and/or eschar.

- Suspected deep tissue pressure injury (SDTI): depth unknown

Persistent, non-blanchable deep red, maroon, purple discoloration or blood-filled blister.

Operating room-acquired SDTIs may not appear until 48 hours after surgery. ${ }^{12}$ They may be confused with electrical injury from energy-generating devices or chemical burns from antiseptic prep solutions. Other types of pressure injuries include medical device-related pressure injury $^{13}$ and mucosal membrane pressure injury, which describes injuries that often conform to the shape of the medical device that is present or was previously in place. ${ }^{14}$ Among patients in acute-care hospitals, HAPI prevalence ranges from $10 \%$ to $17 \% .{ }^{15}$ In $2009,3.3 \%$ of patients in intensive care units in the United States developed a severe facility-acquired pressure ulcer defined as stage III, stage IV, unstageable, or deep tissue injury. ${ }^{16}$ Using the US Nationwide Inpatient Sample Database, a 5-year analysis between 2008 and 2012 identified an average of $>670,000$ patients per year who developed HAPI. Of this group, $16 \%$ were stage $1,38 \%$ were stage $2,20 \%$ were stage 3 , $19 \%$ were stage 4 , and $7 \%$ were unstageable. ${ }^{17}$ As high as $23 \%$ of hospital-acquired pressure ulcers have been shown to have originated in the operating room. ${ }^{18}$ To date, no information regarding prevalence of HAPI by stage in cardiac surgery patients has been published. A HAPI rate as high as $65 \%$ has been reported in patients receiving extracorporeal membrane oxygenation. ${ }^{19}$

\section{HAPI RISK FACTORS}

HAPI pathogenesis is multifactorial and mediated by both pressures of varying intensity and duration composed of compressive and shearing forces, which reduces blood supply and tissue tolerance composed of an individuals' tolerance for pressure based on factors such as age and nutritional status plus oxygen supply and requirements. ${ }^{3,20,21}$ The interplay between the 2 factors mediates tissue damage (Figure 2).

Unique preoperative, intraoperative, and postoperative factors may account for the extraordinarily high risk of HAPI in cardiac surgery patients. Preoperative causes include advanced age, low or high body mass indices, suboptimal nutritional status, anemia, renal dysfunction with creatinine $>3 \mathrm{mg} / \mathrm{dL}$ or hemodialysis, previous or current tobacco use, diabetes, vascular disease, incontinence, decreased mobility or gait disturbances, impaired skin integrity in the area at risk, and previous HAPI. ${ }^{2-25}$ Relevant intraoperative events include skin shearing during transfers, pressure on bony prominences due to inadequate protection, friction due to frequent operating table adjustments, prolonged anesthesia preparation time, use of cardiopulmonary bypass, procedure duration $>3$ hours, ${ }^{26,27}$ hypothermia, hypotension, blood loss, and

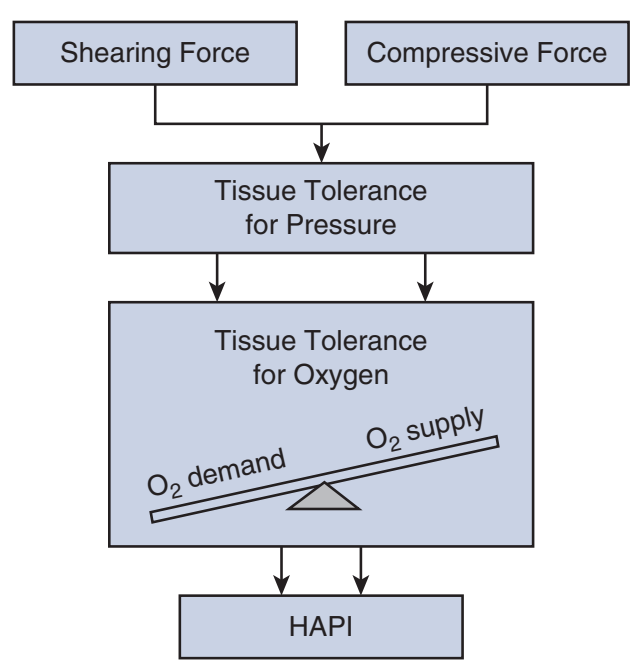

FIGURE 2. A schema of HAPI-causative factors. HAPI, Hospitalacquired pressure injury. 
hypoxia. ${ }^{22-25}$ Postoperative elements include intensive care unit length of stay $>3$ days, use of vasoactive agents, transfusion, mechanical ventilation with elevated head of bed, prolonged sedation, corticosteroid use, need for intraaortic balloon pump or mechanical circulatory support, and lack of timely/adequate repositioning ${ }^{28}$ (Table 1).

Although further investigation is required to better assess the inter-relationship of these various factors, it is most likely that when a cardiac surgery patient develops a HAPI within days after procedure, it first developed during the operation. ${ }^{29}$

\section{HAPI MEASUREMENT}

Developed in 1987, the Braden score is a clinically validated tool ${ }^{30}$ that health care providers can use in conjunction with clinical judgment to assess a patient's risk of developing HAPI. ${ }^{31}$ Ranging from a total score of 6 to 23 , the 6 subscales measured include sensory perception, moisture, activity, mobility, nutrition, and friction/ shear. Patients are then classified into 1 of 4 risk categories for HAPI development: mild (15-18), moderate (13-14), high (10-12), or severe risk $(\leq 9) .{ }^{32}$

The Braden scale has been found to have mixed results in acute-care settings. ${ }^{30}$ In critical care patients, the subscales of sensory perception, mobility, moisture, fracture, and shear were found to be associated with an increased likelihood for HAPI development, whereas the subscales of activity and nutrition were found to not be significantly predictive. $^{33}$ Thus, modified Braden score scales have been proposed, some of which now include "body build for height" and "skin type," with exclusion of the nutrition subscale. ${ }^{34}$ It has been reported to have a low predictive validity with an estimated sensitivity of 0.42 and a specificity of $0.84 .{ }^{35}$ Therefore, multiple other scales were investigated for surgical patients. The commonly used Norton scale ${ }^{36}$ included subscale measurements such as physical condition, mental status, activity, mobility, and incontinence. It has been found to have comparable sensitivity to the Braden scale but lower specificity. Within a cardiac surgery population, no scale was satisfactory. ${ }^{37}$

\section{HAPI TREATMENT}

Once formed, a myriad of treatments for HAPI have been proposed. Interventions such as pressure relief, infection control, debridement, and dressings (eg, gauze, alginate, foam, hydrocolloid, hydrogel, silver-containing dressings, honey-coating dressings, transparent film dressings, negative pressure wound therapy) may be used. Other treatments include recombinant platelet-derived growth factor, electrical stimulation, electromagnetic agents, pulsed radiofrequency energy, phototherapy, acoustic energy, hydrotherapy, or oxygen therapy. ${ }^{38}$ Current thinking places a greater emphasis on prevention. A multimodality approach including use of an assessment tool with
TABLE 1. HAPI risk factors for cardiac surgery patients

\begin{tabular}{ll}
\hline Preoperative: & Intraoperative: \\
- Advanced age & - Skin shearing during transfers \\
- Low of high body mass indices & - Pressure on bony prominences \\
- Suboptimal nutritional status & due to inadequate protection \\
- Anemia & - Friction due to frequent \\
- Renal dysfunction with & operating table adjustments \\
creatinine $>3 \mathrm{mg} / \mathrm{dL}$ or & - Prolonged anesthesia \\
hemodialysis & preparation time \\
- Previous or current tobacco use & - Use of cardiopulmonary bypass \\
- Diabetes & - Procedure duration $>3$ h \\
- Vascular disease & - Hypothermia \\
- Incontinence & - Hypotension \\
- Decreased mobility or gait & - Blood loss \\
disturbances & - Hypoxia \\
- Impaired skin integrity in the & \\
area at risk & \\
- Previous HAPI & \\
Postoperative: & \\
- Intensive care unit length of stay $>3 \mathrm{~d}$ \\
- Use of vasoactive agents \\
- Transfusion
\end{tabular}

HAPI, Hospital-acquired pressure injury; $I A B P$, intra-aortic balloon pump.

appropriate documentation, proper surface support, routine turning and repositioning, as well as adequate nutrition are now standard.

\section{HAPI PREVENTION}

Due to the significant burden HAPI places on both patients and health care organizations, prevention is critical. The use of silicone foam dressings when used prophylactically has been found to be superior to standard HAPIprevention protocols. ${ }^{39}$

For patients admitted via an emergency department, it has been recommended to begin pressure ulcer prevention early if they were likely to undergo surgery or stay in a critical care unit. A 5-layer silicone-bordered dressing was shown to reduce sacral pressure ulcers in conjunction with routine prevention practices. ${ }^{40} \mathrm{~A}$ large retrospective observational cohort study of US acute-care academic medical centers showed that the use of 5-layer silicone-bordered dressings resulted in statistically significant and clinically meaningful decreases in HAPI. ${ }^{41}$ This was also shown in surgical intensive care patients. ${ }^{42}$ Further studies have confirmed clinical efficacy and cost-effectiveness. ${ }^{43-46}$ In addition, it was also demonstrated in a randomized trial ${ }^{47}$ and in a review of nonexperimental prospective studies. ${ }^{48}$

Prophylactic silicone foam dressings have 4 potential inter-related mechanisms of action ${ }^{49}$ : 
1. Pressure redistribution: The presence of a dressing with adequate thickness distributes forces over a larger area, thus accomplishing pressure redistribution by reducing the percentage of magnitude of forces applied to the skin.

2. Shear redistribution: The dressing translates shear force to the skin outside the area of concern. Within the dressing itself, the interface of multiple layers aids in the absorption of shear. The elastic nature of the silicone adhesive also absorbs shear.

3. Friction reduction: The texture and material of construction of the dressing's outer layer is "slippery." Friction is the result of 2 surfaces moving relative to each other and decreasing friction reduces shear forces.

4. Microclimate management: The dressing maintains an optimal level of humidity at the skin surface, which maximizes resilience by avoiding either excessive dryness or maceration predisposing to skin breakdown.

\section{HAPI IN CARDIAC SURGERY PATIENTS}

The use of wound dressings as a potential additional protective means for the prevention of pressure injuries has been investigated over the past 20 years. ${ }^{50}$ The protective mechanisms underlying the use of such dressings is through the reduction of tissue loading and internal deformations by creating an interface between the patient and support surface ${ }^{51}$ Its first use in cardiac surgery patients was described in 2012. ${ }^{52}$ In this small, single-center nonrandomized study, silicone foam dressings were placed perioperatively and patients monitored during their time in a cardiac surgery intensive care unit. Of those receiving "standard" care, 4 of 35 developed HAPI (11\%) versus 1 of $50(2 \%)$ of those receiving a sacral dressing. A subsequent larger study of elective cardiac surgery procedures found no occurrence of SDTI in 224 patients measured at 5 days postoperatively in whom silicone foam dressings were prophylactically applied to the sacrum preoperatively versus a $2.33 \%$ incidence in 300 historic controls. ${ }^{53}$ Our own work,${ }^{54}$ which began as a quality-improvement initiative, now totals more than 300 consecutive patients and included all major cardiac surgery procedures (none requiring or involving mechanical circulatory support). The only exclusion criterion was reported allergy to the dressing material, of which there were none. After a skin assessment, a silicone foam dressing was applied preoperatively either on a patient's hospital unit for urgent or emergent procedures or in the holding area for elective cases. Proper placement was confirmed and documented by the operating room nursing team. The dressing remained in place throughout the patient's stay in the intensive care unit and until the time of their first shower, which was typically on the morning of postoperative day 3 . Total average length of stay postoperatively was 4 days. Sacral skin integrity was formally assessed preoperatively, following dressing removal, before discharge and 30 days postoperatively. For virtually all patients, only a single dressing was required during hospitalization. During the study period, only 1 patient developed an SDTI, which was completely resolved by postoperative day 30. Overall, a HAPI incidence of $<0.30 \%$ was achieved. As HAPI were only reported anecdotally and not formally tracked before the initiation of the study, a baseline incidence could not be accurately established.

\section{EXTENSION OF HAPI PROPHYLAXIS}

As a result of the dramatic results in cardiac surgery patients, the wound care team at our 4-hospital health care system has undertaken an initiative to extend the use of prophylactic sacral silicone foam dressings to other patients. High-risk inclusion criteria will include any patient who meets 1 of the following: recent cardiac arrest, vasopressor medications for $>48$ hours, mechanical ventilation $>48$ hours, septic/hypovolemic/cardiogenic shock, history of sacral/coccygeal pressure ulcers, current redness in the sacral/coccygeal area, ejection fraction $<25 \%$, anticipated operative procedure lasting more than 4 hours in the supine position, quadriplegic/paraplegic/hemiplegic status, cerebral vascular accident, traction, or inability to reposition oneself. Patients will be additionally included should they have 3 or more of the following criteria: body mass index $>35$ or $<18$, Braden score $<18$, weeping edema or anasarca, left ventricular assist device, right ventricular assist device, or intra-aortic balloon pump drive lines in place, age $>70$ years, diabetes, renal failure, liver failure, malnutrition (albumin $<2.5 \mathrm{~g} / \mathrm{dL}$ ), and bed rest for a minimum of 4 hours. However, as a single-center study with indeterminate historical controls, the applicability and external validity of our results is uncertain. Findings should be validated in a large, multicenter study involving a matched control group with appropriate randomization processes and long-term follow-up. The fundamental issue that hinders evidencebased progress in this area is that prevention, as opposed to therapeutic efficacy, is difficult to prove. Assuming a HAPI incidence of only $10 \%$ over a 1 -year period, this would require examining 1000 patients in a treatment group and 1000 patients in a control group to compare and determine statistically significant differences. Such a large trial is not anticipated in the near future. Additionally, there are currently 4 major marketed silicone foam dressings: Allevyn (Smith \& Nephew, London, United Kingdom), Aquacel (ConvaTex, Inc, Deeside, United Kingdom), Mepilex (Mölnlycke Health Care, Gothenburg, Sweden), and Optifoam (Medline, Northfield, Ill). All have somewhatdifferent construction and intrinsic properties. Few published head-to-head data regarding clinical superiority exist. A critical analysis of current testing of silicone foam dressings highlights the benefits and faults of current biomechanical and clinical research in a call for higher 
standards in the field. ${ }^{50}$ The use of steel ball testing to obtain interface pressure measurements using a threshold of $32 \mathrm{~mm} \mathrm{Hg}$ as a supposed baseline for capillary closure resulting in tissue hypoxia is disputed. Presumably this testing method does not adequately or accurately simulate the anatomy, physiology, or biomechanics of the human body. Alternative approaches with these considerations in mind need to be developed to properly determine superiority amongst the various brands.

\section{ADVANTAGE OF HAPI REDUCTION}

Although most commonly attributed to Benjamin Franklin, the aphorism, "An ounce of prevention is worth a pound of cure. It's more prudent to head off a disaster actually beforehand than to deal with it after it occurs," can actually be traced to Henry de Bracton's De Legibus et Consuetudinibus Angliae. Whether referring to 18th-century Philadelphia firefighting readiness, 13th-century English jurisprudence, or 21st-century medical care, it is axiomatic that both the direct and indirect costs of inadequate deterrence are significant. Patients undergoing cardiac surgery are at particularly increased risk for HAPI. Preoperative prophylactic placement of a silicone foam dressing on the sacrum is a fiscally prudent and transformative method of preventing a profoundly debilitating condition. It can result not only in potentially significant cost savings through reduced use of hospital resources and shortened length of stay, but also in improved patient, family, and staff satisfaction. The NPUAP/European Pressure Ulcer Advisory Panel 2014 guidelines include a level of evidence B recommendation to "consider applying a polyurethane foam dressing to bony prominences (eg, heels, sacrum) for the prevention of pressure ulcers in anatomical areas frequently subjected to friction and shear." ${ }^{55}$ Updated guidelines are presently pending. Based on size, shape, and manufacturer, the average cost of such a dressing in 2011 was just over $\$ 7 .{ }^{56}$ Currently, the most expensive such dressing marketed typically costs less than $\$ 11$. Given that it costs more than $\$ 40,000$ to treat a single HAPI, the decision is clear. Multidisciplinary approaches have been shown to reduce the incidence of HAPI development in cardiac surgery patients. Implementation of institutional protocols such as formal mandatory staff education, development of turning guidelines, use of skin care bundles, and clinical coaching have been shown to decrease the rate of development of HAPI by $44 \%$ in patients with ECMO ${ }^{19}$ In conjunction with additional standard prevention methods such as skin risk assessment, appropriate surface support, and adequate nutrition, preoperative prophylactic sacral silicone foam dressing application should be considered as a new standard of care and included as a component in the next iteration of the Enhanced Recovery After Surgery guidelines for perioperative care in cardiac surgery. ${ }^{57}$

\section{Conflict of Interest Statement}

Authors have nothing to disclose with regard to commercial support.

\section{References}

1. Adams F. The Genuine Works of Hippocrates [Translated from the Greek] Baltimore, MD: Williams and Wilkins; 1939:231-42.

2. Agrawal K, Chauhan N. Pressure ulcers: back to basics. Indian J Plast Surg. 2012;45:244-54.

3. Feuchtinger J, Halfens RJ, Dassen T. Pressure ulcer risk factors in cardiac surgery: a review of the research literature. Heart Lung. 2005;34:375-85.

4. Castelino I. Reducing pressure ulcers in thoracic, cardiovascular and spinal surgery patients: achieving ZERO incidence is possible. Atlanta, GA: Presented at: Symposium on Advanced Wound Care; April 19-22, 2012.

5. Lu CX, Chen HL, Shen WQ, Feng LP. A new nomogram score for predicting surgery-related pressure ulcers in cardiovascular surgical patents. Int Wound J. 2017; 14:226-32.

6. Russo CA, Steiner C, Spector W. Hospitalizations Related to Pressure Ulcers, 2006. HCUP Statistical Brief \#64 2008. Rockville, MD: Agency for Healthcare Research and Quality. Available at: http://www.hcup-us.ahrq.gov/reports/ statbriefs/sb64.pdf. Accessed October 18, 2019

7. Are we ready for this change? Rockville, MD: Agency for Healthcare Research and Quality. Available at: https://www.ahrq.gov/patient-safety/settings/hospital/ resource/pressureulcer/tool/pu1.html. Accessed October 18, 2019.

8. Primiano M, Friend M, McClure C, Nardi S, Fix L, Schafer M, et al. Pressure ulcer prevalence and risk factors among prolonged surgical procedures in the OR. AORN J. 2011;94:555-66.

9. Centers for Medicare \& Medicaid Services. Incorporating Selected Quality Forum and never events into Medicare's list of hospital acquired conditions. Available at: http://www.cms.gov/Newsroom/MediaReleaseDatabase/FactSheets/2008-Fact-Sheets-Items/2008-04-142.html. Accessed October 18, 2019.

10. Edsberg LE, Black JM, Goldberg M, McNichol L, Moore L, Sieggreen M Revised national pressure ulcer advisory panel pressure injury staging system: revised pressure injury staging system. J Wound Ostomy Continence Nurs 2016;43:585-97.

11. National Pressure Ulcer Advisory Panel, European Pressure Ulcer Advisory Panel, Pan Pacific Pressure Injury Alliance. In: Haesler Emily, ed. Prevention and Treatment of Pressure Ulcers: Quick Reference Guide. Osborne Park, Australia: Cambridge Media; 2014.

12. Association of Perioperative Registered Nurses. Recommended practices for positioning the patient in the perioperative setting. AORN J. 2001;73:231-5, 237-8.

13. Levy A, Kapplin K, Gefen A. Device related pressure ulcers from a biomechanical perspective. J Tissue Viability. 2017;26:57-68.

14. National Pressure Ulcer Advisory Panel. Mucosal Pressure Ulcers: an NPUAP Position Statement. Available at: http://www.npuap.org/wp-content/uploads/ 2012/03/Mucosal_Pressure_Ulcers_Position_Statement_final.pdf. Accessed October 18, 2019.

15. Vanderwee K, Clark M, Dealey C, Gunningberg L, Defloor T. Pressure ulcer prevalence in Europe: a pilot study. J Eval Clin Pract. 2007;13:227-35.

16. VanGuilder C, Amlung S, Harrison P, Meyer S. Results of the 2008-2009 international pressure ulcer prevalence TM survey and a 3-year, acute care, unit-specific analysis. Ostomy Wound Manage. 2009;55:39-45.

17. Bauer K, Rock K, Nazzal M, Jones O, Qu W. Pressure ulcers in the United States inpatient population from 2008 to 2012: results of a retrospective nationwide study. Ostomy Wound Manage. 2016;62:30-8.

18. Gefen A. How much time does it take to get a pressure ulcer? Integrated evidence from human, animal, and in vitro studies. Ostomy Wound Manage. 2008;54:26-8. $30-5$.

19. Clements L, Moore M, Tribble T, Blake J. Reducing skin breakdown in patients receiving extracorporeal membranous oxygenation. Nurs Clin North Am. 2014; 49:61-8.

20. Defloor T. The risk of pressure sores: a conceptual scheme. J Clin Nurs. 1999;8: 206-16.

21. Benoit R, Mion L. Risk factors for pressure ulcer development in critically ill patients: a conceptual model to guide research. Res Nurs Health. 2012;35:340-62.

22. Lindgren M, Unosson M, Krantz AM, Ek AC. Pressure ulcer risk factors in patients undergoing surgery. J Adv Nurs. 2005;50:605-12.

23. Gao L, Yang L, Li X, Chen J, Du J, Yang H. Risk factors for intraoperative pressure ulcers in surgical patients. Int J Clin Exp Med. 2018;11:7429-35. 
24. Keller P, Wille J, van Ramshorst B, van der Werken C. Pressure ulcers in intensive care patients: a review of risks and prevention. Intensive Care Med. 2002;28: 1379-88.

25. Rao A, Preston A, Strauss R, Stamm R, Zalman D. Risk factors associated with pressure ulcer formation in critically ill cardiac surgery patients. J Wound Ostomy Continence Nurs. 2016:43:242-7.

26. King CA, Bridges E. Comparison of pressure relief properties of operating room surfaces. Perioper Nurs Clin. 2006;1:261-5.

27. O'Connell MP. Positioning impact on the surgical patient. Nurs Clin North Am. 2006;41:173-92.

28. Chello C, Lusini M, Schiliro D, Greco SM, Barbato R, Nenna A. Pressure ulcers in cardiac surgery: few clinical studies, difficult risk assessment, and profound clinical implications. Int Wound J. 2019;16:9-12.

29. Papantonio CT, Wallop JM, Kolodner KB. Sacral ulcers following cardiac surgery: incidence and risks. Adv Wound Care. 1994;72:24-36.

30. Hyun S, Vermillion B, Newton C, Fall M, Li X, Kaewprag P, et al. Predictive validity of the Braden scale for patients in intensive care units. Am J Crit Care. 2013;22:514-20.

31. Bergstrom N, Braden BJ, Laguzza A, Holman V. The Braden scale for predicting pressure sore risk. Nurs Res. 1987;36:205-10.

32. The Braden Scale. Prevention Plus [Internet]. Omaha. NE: Prevention Plus; c2000, 2001. Available at: http://www.bradenscale.com/bradenscale.htm. Accessed October 18, 2019.

33. Cox J. Predictive power of the Braden scale for pressure sore risk in adult critical care patients. J Wound Ostomy Continence Nurs. 2002;39:613-21.

34. Chan WS, Pang SM, Kwong EW. Assessing predictive validity of the modified Braden scale for prediction of pressure ulcer risk of orthopaedic patients in an acute care setting. J Clin Nurs. 2009;18:1565-73.

35. He W, Liu P, Chen HL. The Braden Scale cannot be used alone for assessing pressure ulcer risk in surgical patients: a meta-analysis. Ostomy Wound Manage. 2012;58:34-40

36. Norton D, McLaren R, Exton-Smith AN. An investigation of geriatric nursing problems in a hospital. J Gerontol. 1963;18:290-1.

37. Feuchtinger J, Halfens R, Dassen T. Pressure ulcer risk assessment immediately after cardiac surgery - does it make a difference? A comparison of three pressure ulcer risk assessment instruments within a cardiac surgery population. Nurs Crit Care. 2007; 12:42-9.

38. Boyko TV, Longaker MT, Yang GP. Review of the current management of pressure ulcers. Adv Wound Care. 2018;7:57-67.

39. Truong B, Grigson E, Patel M, Liu X. Pressure ulcer prevention in the hospital setting using silicone foam dressings. Cureus. 2016;8:e730.

40. Black J, Clark M, Dealey C, Brindle CT, Alves P, Santamaria N, et al. Dressings as an adjunct to pressure ulcer prevention: consensus panel recommendations. Int Wound J. 2015;12:484-8.

41. Padula WV. Effectiveness and value of prophylactic 5-layer foam sacral dressings to prevent hospital-acquired pressure injuries in acute care hospitals: an observational cohort study. J Wound Ostomy Cont Nurs. 2017;44: 413-9.

42. Brindle C. Outliers to the Braden scale: identifying high-risk ICU patients and the result of prophylactic dressing use. WCET J. 2010;30:2-8.
43. Santamaria N, Gerdtz M, Sage S, McCann J, Freeman A, Vassiliou T, et al. A randomised controlled trial of the effectiveness of soft silicone multi-layered foam dressings in the prevention of sacral and heel pressure ulcers in trauma and critically ill patients: the border trial. Int Wound J. 2015;12:302-8.

44. Santamaria N, Santamaria H. An estimate of the potential budget impact of using prophylactic dressings to prevent hospital-acquired PUs in Australia. J Wound Care. 2014;23:583-4.

45. Santamaria N, Liu W, Gerdtz M, Sage S, McCann J, Freeman A, et al. The costbenefit of using soft silicone multilayered foam dressings to prevent sacral and heel pressure ulcers in trauma and critically ill patients: a within-trial analysis of the Border trial. Int Wound J. 2015;12:344-50.

46. Santamaria N, Gerdtz M, Liu W, Rakis S, Sage S, Ng AW, et al. Clinical effectiveness of a silicone foam dressing for the prevention of heel pressure ulcers in critically ill patients: Border II trial. J Wound Care. 2015;24:340-50.

47. Kalowes P, Li M, Carlson C, Carr L, Llantero L, Lukaszka D, et al. Use of a soft silicone, self-adherent, bordered foam dressing to reduce pressure ulcer formation in high risk patients: a randomized clinical trial. Presented at: Journal of Wound Ostomy and Continence Nursing; June 22-26, 2013; Seattle Wash.

48. Davies P. Role of multi-layer foam dressings with Safetac in the prevention of pressure ulcers: a review of the clinical and scientific data. $J$ Wound Care. 2016;25(1 suppl):S1,S4-S23.

49. Schwartz D, Levy A, Gefen A. A computer modeling study to assess the durability of prophylactic dressings subjected to moisture in biomechanical pressure injury prevention. Ostomy Wound Manag. 2018;64:18-26.

50. Gefen A, Kottner J, Santamaria N. Clinical and biomechanical perspectives on pressure injury prevention research: the case of prophylactic dressings. Clin Biomech. 2016:38:29-34.

51. Levy A, Frank MB, Gefen A. The biomechanical efficacy of dressings in preventing heel ulcers. J Tissue Viability. 2015;24:1-11.

52. Brindle CT, Wegelin JA. Prophylactic dressing application to reduce pressure ulcer formation in cardiac surgery patients. J Wound Ostomy Cont Nurs. 2012; 39:133-42.

53. Strauss R, Preston A, Zalman DC, Rao AD. Silicone foam dressing for prevention of sacral deep tissue injuries among cardiac surgery patients. Adv Ski Wound Care. 2019;32:139-42.

54. Geller CM. Hospital-acquired pressure injury prevention utilizing prophylactic silicone foam dressings in cardiac surgery patients. Presented at: 16th Annual STS Cardiothoracic Surgery Critical Care Conference; Sept 2019; Baltimore, Md.

55. National Pressure Ulcer Advisory Panel, European Pressure Ulcer Advisory Panel, Pan Pacific Pressure Injury Alliance. Prevention and Treatment of Pressure Ulcers Clinical Practice Guideline. Washington, DC: National Pressure Ulcer Advisory Panel; 2014.

56. Padula WV, Mishra MK, Makic MB, Sullivan PW. Improving the quality of pressure ulcer care with prevention: a cost-effectiveness analysis. Med Care. 2011; 49:385-92.

57. Engelman DT, Ben Ali W, Williams JB. Guidelines for perioperative care in cardiac Surgery Enhanced Recovery after Surgery society recommendations. JAMA Surg. 2019;154:755-66. 